\title{
Effect of germinated brown rice extracts on pancreatic lipase, adipogenesis and lipolysis in 3T3-L1 adipocytes
}

\author{
See Meng Lim', Yong Meng Goh², Wen Bin Kuan ${ }^{3}$ and Su Peng Loh ${ }^{1^{*}}$
}

\begin{abstract}
Background: This study investigated anti-obesity effects of seven different solvent (n-hexane, toluene, dicholoromethane, ethyl acetate, absolute methanol, $80 \%$ methanol and deionized water) extracts of germinated brown rice (GBR) on pancreatic lipase activity, adipogenesis and lipolysis in 3T3-L1 adipocytes.

Methods: GBR were extracted separately by employing different solvents with ultrasound-assisted. Pancreatic lipase activity was determined spectrophotometrically by measuring the hydrolysis of $p$-nitrophenyl butyrate ( $p$-NPB) to $p$-nitrophenol at $405 \mathrm{~nm}$. Adipogenesis and lipolysis were assayed in fully differentiated 3T3-L1 adipocytes by using Oil Red $O$ staining and glycerol release measurement.

Results: GBR extract using hexane showed the highest inhibitory effect $(13.58 \pm 0.860 \%)$ at concentration of $200 \mathrm{\mu g} / \mathrm{ml}$ followed by hexane extract at $100 \mu \mathrm{g} / \mathrm{ml}(9.98 \pm 1.048 \%)$ while ethyl acetate extract showed the lowest $(2.62 \pm 0.677 \%)$ at concentration of $200 \mathrm{\mu g} / \mathrm{ml}$ on pancreatic lipase activity. Water extract at $300 \mu \mathrm{g} / \mathrm{ml}$ showed $61.55 \pm 3.824 \%$ of Oil Red O staining material (OROSM), a marker of adipogenesis. It significantly decrease $(p<0.05)$ lipid accumulation than control (OROSM $=100 \%)$, follow by ethyl acetate extract at $300 \mu \mathrm{g} / \mathrm{ml}$ (OROSM $=65.17 \pm 3.131 \%)$. All the GBR extracts induced lipolysis with 1.22-1.83 fold of greater glycerol release than control.

Conclusions: GBR extracts especially the least polar and intermediate polar solvent extracts exhibited inhibitory effect on pancreatic lipase, decrease fat accumulation by adipocyte differentiation inhibition, and stimulate lipolysis on adipocytes. Therefore, GBR could be furthered study and developed as a functional food in helping the treatment and/or prevention of obesity.
\end{abstract}

Keywords: Obesity, Germinated brown rice, Pancreatic lipase, 3T3-L1 adipocytes

\section{Background}

Overweight and obesity are chronic metabolic disorder caused by an imbalance between food intake and energy expenditure [1]. Pancreatic lipase, the key lipid digesting enzyme secreted by the pancreatic acinar cells [2], is responsible for the hydrolysis of about $50-70 \%$ of total dietary fats [3]. The digested fat is either use as energy source or absorbed and accumulated into adipocytes. Excessive differentiation in the number (hyperplasia) and/or size (hypertrophy) of adipocytes are the characteristics in obesity [4]. Adipocytes are not only fat storage

\footnotetext{
*Correspondence: sploh@upm.edu.my

'Department of Nutrition and Dietetics, Faculty of Medicine and Health Sciences, Universiti Putra Malaysia, 43400 Serdang, Selangor, Malaysia Full list of author information is available at the end of the article
}

cells but are active endocrine organs secreting adipokines that regulate multiple metabolic homeostasis [5]. Therapeutics for obesity that targeted on these two approaches are lipase inhibition, adipocytes differentiation inhibition and promote lipid metabolism [6]. Although few antiobesity drugs that are available in the market are meant for therapeutic approach, most of them have adverse side effects [7]. Orlistat (Xenical $\left.{ }^{\mathrm{m}}\right)$, a specific pancreatic lipase inhibitor clinically approved by Food and Drug Administration could block approximately 30\% absorption of dietary fat [8]. However, the uses of orlistat have been reported with some adverse effects which include oily stools, diarrhea, flatulence, bloating, abdominal pain, dyspepsia, and fecal spotting $[9,10]$. The existing side effects and failure of drugs to continue to be used in 
long term management, elucidated the need for efficacious yet safe treatments to help prevent disease progression and protect patients from weight regain [11,12]. Many novel research works have recently come to the fore in discovering potential anti-obesity effect especially from natural sources with the inhibition of fat absorption and/or fat accumulation in the body by interrupting the lipase and adipocyte activity [13-16]. According to Birari et al., [3], natural products might be an excellent alternative strategy for the development of safe and effective anti-obesity drugs yet much of them are still unexplored.

Rice (Oryza sativa L.) is a major staple food for more than half of the world's population especially people in Asia and as the second-most consumed cereal grain $[17,18]$. It is a main source of energy and accounts for nearly quarter of global energy intake [19]. Germinated brown rice (GBR) is produced by soaking the whole kernel of brown rice in water until it produced a germ of approximately $1 \mathrm{~mm}$ long [20]. During the process of germination, the chemical compositions of the rice change drastically. All the dormant enzymes are activated to break down the large molecular substances, generating essential compounds and energy $[21,22]$. The amount of nutrients such as $\gamma$-aminobutyric acid (GABA) [23-25], ferulic acid [19], phytic acid [26], dietary fiber [26], tocotrienols [25], some minerals (magnesium, potassium, zinc), $\gamma$-oryzanol [27], prolylendopeptidase inhibitor and antioxidants compounds [28] showed significant increased after germination. The palatability and texture of GBR were also noted to have improved after germination [29]. Research that focus on diminishing fat hydrolysis and their absorption in the gastrointestinal tract through the use of GBR could be an alternative prescription in reducing fat digestion and fat deposition.

In recent times, ultrasound-assisted extraction (UAE) has been extensively applied to extract active compounds from plant materials such as traditional Chinese medicine [30,31], fruits [32], soy products [33], seed [34], and wheat germ [35]. UAE decrease extraction time and increase extraction yields to minimize problems such as long extraction time and require relatively large quantities of solvent that faced by conventional extraction methods like maceration extraction and soxhlet extraction [30,36]. In this study, crude extracts of GBR from different polarity solvents with ultrasound-assisted were screened for potential anti-obesity effects by examining their lipase inhibition activity supplemented with their effects on adipogenesis and lipolysis in cultured 3T3-L1 adipocytes.

\section{Results and discussion}

Ultrasound-assisted extraction yields

Extraction is the initial step in isolating phytochemicals from plant materials [37]. Polarity of solvent and plant matrix will influence the efficiency of extracting the bioactive compounds from the sample [31,37]. Thus, selection of the most appropriate solvent for extracting bioactive compounds from sample is a crucial process for investigates any experiments. Usually the least polar solvents are considered to be suitable for the extraction of non-polar fraction [38]. A similar principal is applied to semi-polar and polar fraction. Seven different solvents with a wide range of polarities ( $n$-hexane, toluene, dicholoromethane, ethyl acetate, absolute methanol, $80 \%$ methanol and deionized water) were used to extract the bioactive compounds of GBR under the same conditions. UAE had been applied in this present study due to the fact that UAE can reduce the extraction time, reduce solvent consumption and give higher yield of bioactive compounds [30,36].

The results of extraction yields are summarized in Table 1. Overall, water extract $(5.91 \pm 0.853 \%)$ gave the highest extraction yields, followed by toluene $(2.68 \pm 0.393 \%)$ and ethyl acetate $(2.61 \pm 0.136 \%)$. The findings of this study were similar to the oil extraction yield of rice bran by hot air, microwave, roasting, and steaming which were $5.53 \%$, $4.81 \%, 4.77 \%$ and $3.41 \%$, respectively [39]. The reason for higher yield for water extraction might be longer heating time caused excessive swelling of the material such as starch when only water is used as the solvent [40]. The starch in water forms more floccule that could adsorb the effective compounds extracted [40]. Besides, different polarity and viscosity of the solvent used might influence the extraction efficiency [31]. A few studies reported that the additional of small percentages of water to the extraction solvent can sometime help to increase extraction yield $[41,42]$. The extract yield of $80 \%$ methanol $(1.79 \pm 0.292 \%)$ showed higher yield than absolute methanol $(1.20 \pm 0.206 \%)$ although they were not significantly different $(p>0.05)$.

\section{Pancreatic lipase inhibition}

Pancreatic lipase inhibition is one of the most widely used models to investigate the potential efficacy of natural products as anti-obesity drugs [3]. Therefore, pancreatic lipase in vitro model was used to evaluate the inhibitory effect on pancreatic lipase activity of all the GBR extracts at

Table 1 Extraction yields of different solvent of GBR extracts with ultrasound-assisted

\begin{tabular}{ll}
\hline Type of extracts & Yields (\%) \\
\hline Hexane & $2.19 \pm 0.657^{\mathrm{a}, \mathrm{b}}$ \\
Toluene & $2.68 \pm 0.393^{\mathrm{b}}$ \\
Dichloromethane & $1.71 \pm 0.066^{\mathrm{a}, \mathrm{b}}$ \\
Ethyl acetate & $2.61 \pm 0.136^{\mathrm{b}}$ \\
Absolute methanol & $1.20 \pm 0.206^{\mathrm{a}}$ \\
80\% Methanol & $1.79 \pm 0.292^{\mathrm{a}, \mathrm{b}}$ \\
Water & $5.91 \pm 0.853^{\mathrm{c}}$ \\
\hline
\end{tabular}

${ }^{a-b}$ Values with different lower case letters are significantly different at $p<0.05$. 
concentration of 100,200 and $300 \mu \mathrm{g} / \mathrm{ml}$ by measuring the hydrolysis of $p$-NPB to $p$-nitrophenol. The antilipase activity was expressed as percentage of inhibition of control at $0 \%$ and is presented in Figure 1. Overall, the inhibitions of pancreatic lipase of various solvent extracts of GBR were ranged from $2.62 \%$ to $13.58 \%$. All the extracts did not suppress pancreatic lipase activity in a dose-dependent manner in the concentration of 100, 200, and $300 \mu \mathrm{g} / \mathrm{ml}$. Extracts at concentration of $100 \mu \mathrm{g} / \mathrm{ml}$ exhibited stronger inhibitory effects than extracts at concentration of $200 \mu \mathrm{g} / \mathrm{ml} \mathrm{al-}$ though some of the extracts were not significantly different $(\mathrm{p}>0.05)$. The inhibitory activities of this study were in line to anti-lipase activities of certain natural plant species found in Korea or Asia [15], with inhibition ranged from $2.5 \%$ to $38 \%$.

The hexane extract of GBR showed significantly higher $(\mathrm{p}<0.05)$ inhibitory effect on pancreatic lipase (7.11$13.58 \%)$ than other extracts. Some non-polar compounds that present in GBR might play an important role in the lipase inhibition. Rice bran oil contains phytosterols that could be present as intermediate products such as cycloartenol and 24-methylene cycloartanol, as well as ferulic acid esters (oryzanol) [43]. According to Zaburuth et al., [44], phytosterols found in hexane extract of Operculina turpethum leaves, showed $44.26 \%$ of inhibition on pancreatic lipase. Orlistat, as a positive control, showed an $\mathrm{IC}_{50}$ of $1.56 \mu \mathrm{g} / \mathrm{ml}\left(\mathrm{y}=10.338 \ln (\mathrm{x})+45.39, \mathrm{r}^{2}=\right.$ 0.979 ) in this study on pancreatic lipase activity but no $\mathrm{IC}_{50}$ was found for all GBR extracts at concentration up to $300 \mu \mathrm{g} / \mathrm{ml}$. The lower potency than orlistat suggests that GBR extracts per se might not as effective as commercial drug in inhibiting of pancreatic lipase activity. This is probably due to the activity of a crude extract includes both active and non-active constituents which could be lower than that of the active constituent alone [45].

Inhibitors of pancreatic lipase play an important role in the treatment of obesity. Through gastrointestinal mechanisms, interfering of nutrient digestion and absorption in the body may attempt to decrease the digestion of fat to free fatty acid and monoglycerides that will be further synthesize and accumulate in the adipocytes [3]. Previous studies done on rice bran have also been reported to reduce the absorption of indigested fat by inhibiting the pancreatic lipase activity $[46,47]$. GBR is rich in bioactive compounds and has inhibitory effect on pancreatic lipase. This is suggesting that it may be a useful alternative to treat obesity by limiting the dietary fat absorption and accumulation of fat in adipocytes since rice is a daily staple food in some of the countries.

\section{Adipocyte cell viability}

MTT assay was done to assess the cell viability of 3T3-L1 preadipocytes treated with various concentrations of GBR extracts. The cell viabilities were ranged from $73.58 \%$ to $108.31 \%$ after $72 \mathrm{hr}$ incubation with the GBR extracts (Table 2). The cell viabilities of extracts at the highest concentration $(300 \mu \mathrm{g} / \mathrm{ml})$ were significantly lower $(\mathrm{p}<0.05)$ than the control (without treatment), but the cell viability of 3T3-L1 preadipocytes treated with GBR water extract did not showed significant differences $(\mathrm{p}>0.05)$ than control. It is because the GBR itself might not toxic to the 3T3L1 preadipocytes, but the solvents that used during extraction might toxic to the cells. In addition, non-cytotoxicity is defined as viability $\geq 70 \%$ compared to untreated cells [48]. All the extracts in different concentrations included

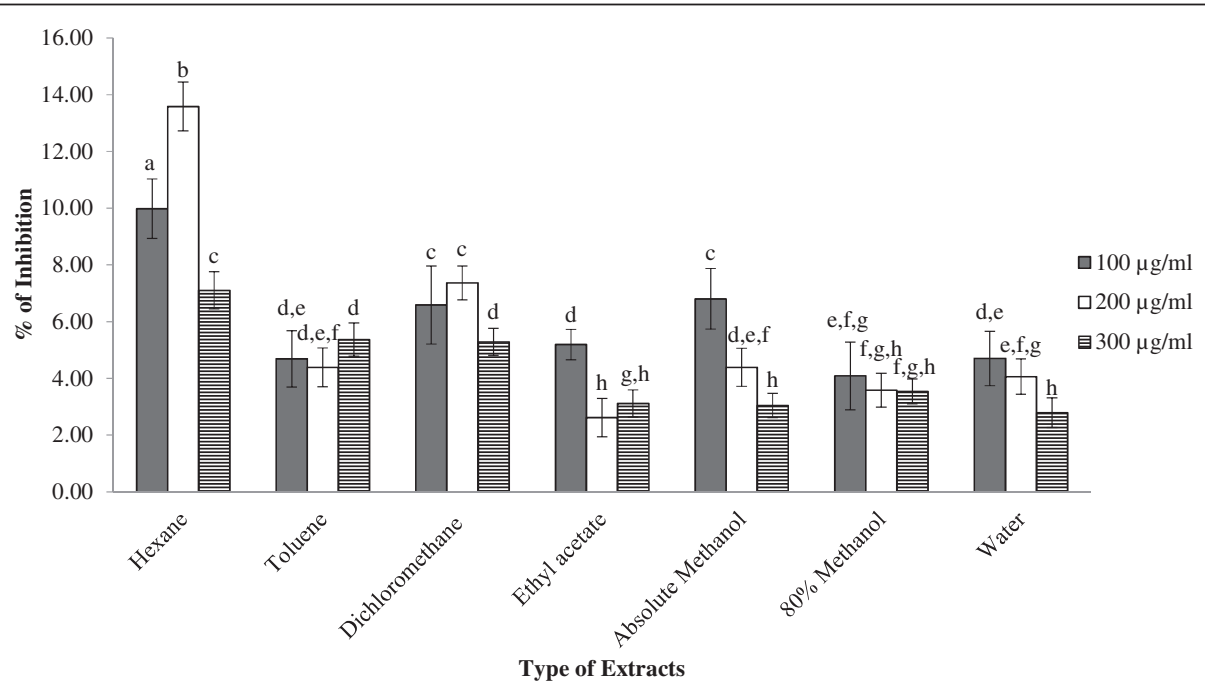

Figure 1 Effect of GBR extracts on pancreatic lipase activity. Results are given as a mean value \pm S.D. of six replicate measurements. Bar graphs represent the $\%$ of inhibition of various GBR extracts in different concentrations on lipase activity. ${ }^{\text {a-h }}$ Values with different lower case letters are significantly different at $p<0.05$. 
Table 2 Effects of GBR extracts on preadipocyte viabilities after $\mathbf{7 2}$ hr incubation

\begin{tabular}{|c|c|c|c|c|c|c|c|}
\hline \multirow[t]{2}{*}{ Type of extracts } & \multicolumn{7}{|c|}{ Concentration $(\mu \mathrm{g} / \mathrm{ml})$} \\
\hline & 0 & 5 & 25 & 50 & 100 & 200 & 300 \\
\hline Hexane & $96.30 \pm 3.249^{a}$ & $92.47 \pm 4.040^{b}$ & $90.22 \pm 1.259^{b}$ & $89.76 \pm 0.826^{b}$ & $86.12 \pm 1.663^{c}$ & $82.48 \pm 3.154^{d}$ & $80.60 \pm 3.120^{d}$ \\
\hline Toluene & $91.31 \pm 2.122^{a}$ & $88.02 \pm 1.777^{b}$ & $81.49 \pm 1.547^{c}$ & $80.45 \pm 1.189^{c}$ & $77.54 \pm 3.144^{d}$ & $76.05 \pm 0.585^{d}$ & $75.31 \pm 1.231^{d}$ \\
\hline Dichloromethane & $90.25 \pm 2.571^{a}$ & $89.24 \pm 1.266^{\mathrm{a}, \mathrm{b}}$ & $88.00 \pm 1.977^{b}$ & $82.69 \pm 0.813^{c}$ & $85.76 \pm 0.823^{d}$ & $87.33 \pm 0.886^{b, d}$ & $78.87 \pm 1.883^{e}$ \\
\hline Ethyl acetate & $90.78 \pm 3.005^{\mathrm{a}}$ & $89.93 \pm 1.068^{\mathrm{a}}$ & $88.89 \pm 3.095^{\mathrm{a}}$ & $88.64 \pm 2.193^{\mathrm{a}}$ & $88.25 \pm 1.471^{a, b}$ & $85.74 \pm 1.726^{b}$ & $73.58 \pm 1.963^{c}$ \\
\hline Absolute methanol & $98.88 \pm 0.565^{\mathrm{a}}$ & $95.69 \pm 2.206^{b}$ & $102.83 \pm 2.619^{c}$ & $107.94 \pm 2.020^{d}$ & $108.31 \pm 1.559^{d}$ & $106.22 \pm 2.792^{d}$ & $105.30 \pm 4.343^{c, d}$ \\
\hline $80 \%$ Methanol & $93.96 \pm 1.051^{a, b}$ & $91.95 \pm 2.077^{\mathrm{a}, \mathrm{c}}$ & $89.37 \pm 2.503^{c, d}$ & $88.94 \pm 0.722^{d}$ & $88.96 \pm 2.916^{d}$ & $94.15 \pm 0.747^{a, b}$ & $95.84 \pm 3.754^{b}$ \\
\hline Water & $91.41 \pm 3.032^{a, b}$ & $89.14 \pm 1.118^{b}$ & $89.18 \pm 3.000^{b}$ & $89.02 \pm 0.464^{b}$ & $87.97 \pm 2.850^{b}$ & $90.32 \pm 2.763^{a, b}$ & $92.88 \pm 3.923^{\mathrm{a}}$ \\
\hline
\end{tabular}

${ }^{a-e}$ Values within a row followed by different lower case letters are significantly different at $\mathrm{p}<0.05$.

the highest concentration $(300 \mu \mathrm{g} / \mathrm{ml})$ were significant higher $(\mathrm{p}<0.001)$ than $70 \%$. Thus, all the extracts at concentration of $0-300 \mu \mathrm{g} / \mathrm{ml}$ were considered as noncytotoxic to 3T3-L1 preadipocytes.

\section{Oil red $\mathbf{O}$ staining for intracellular triglycerides}

Adipose tissue plays an important role in maintaining lipid homeostasis and energy balance by storing triglycerides or liberating free fatty acid in response to changes in energy demands [4]. In Figure 2, the inhibition effects of GBR extracts on fat droplet formation in 3T3-L1 cells, through the quantification method of Oil red $\mathrm{O}$ staining, are presented. Oil red $\mathrm{O}$ staining material (OROSM) was used as a marker of adipogenesis where the higher the OROSM value, the higher the lipid accumulation inside the cells. Basically, most of the GBR extracts significantly reduce $(\mathrm{p}<0.05)$ lipid accumulation in 3T3-L1 adipocytes compared to control (without treatment), except absolute methanol extract at concentration of $100 \mu \mathrm{g} / \mathrm{ml}$ and $200 \mu \mathrm{g} / \mathrm{ml}$ and $80 \%$ methanol extract at concentration of $200 \mu \mathrm{g} / \mathrm{ml}$.

This present study showed that GBR extracts at concentration of $300 \mu \mathrm{g} / \mathrm{ml}$ showed the highest inhibition in lipid accumulation while extracts at concentration of $100 \mu \mathrm{g} / \mathrm{ml}$ and $200 \mu \mathrm{g} / \mathrm{ml}$ were not significant between each other $(p>0.05)$ in reducing lipid accumulation of adipocytes. This implied that although GBR extracts at $100-200 \mu \mathrm{g} / \mathrm{ml}$ were able to reduce the lipid accumulation in the adipocytes, GBR extracts at $300 \mu \mathrm{g} / \mathrm{ml}$ showed better inhibition. The active compounds that were present in the extract might inactivate one/some of the pathways in adipogenesis that lead to the decrease lipid accumulation inside the adipocytes.

Besides, the water extract of GBR at concentration of $300 \mu \mathrm{g} / \mathrm{ml}$ exhibited the lowest OROSM with only $61.55 \pm 3.824 \%$ and followed by ethyl acetate extract at concentration of $300 \mu \mathrm{g} / \mathrm{ml}(\mathrm{OROSM}=65.17 \pm 3.131 \%)$. Meantime, the OROSM of least and intermediate polar

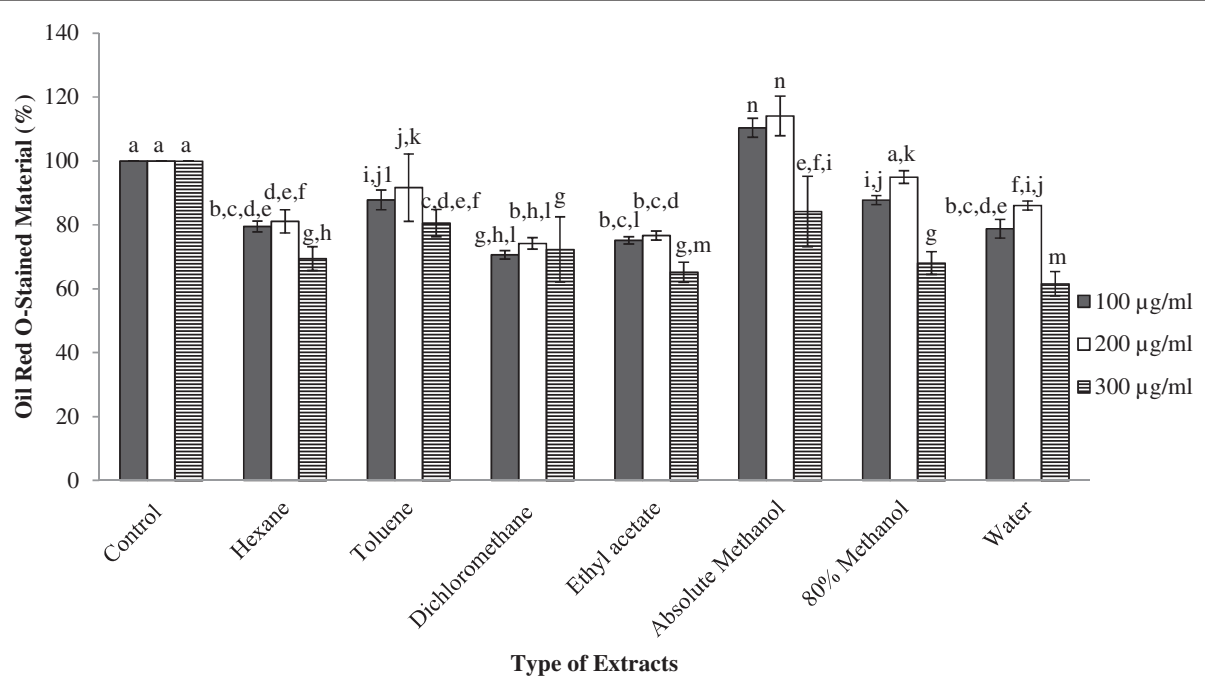

Figure 2 Relative lipid content quantified via Oil Red 0 staining in 3T3-L1 adipocytes. Results are given as a mean value \pm S.D. of six replicate measurements. Bar graphs represent the relative amounts of accumulated lipid in cultured 3T3-L1 adipocytes after treated with various GBR extracts in different concentrations. ${ }^{a-n}$ Values with different lower case letters are significantly different at $p<0.05$. 
solvent extracts are in the range of $65.17 \%$ to $91.64 \%$ compared to OROSM of polar solvent extracts with OROSM of $61.55 \%$ to $114.07 \%$. Lipophilic constituents such as unsaponifiable fraction (phytosterols, triterpene alcohols, 4-methyl-sterols), less polar components (squalene or tocotrienols and $\alpha$-tocopherol), and $\gamma$-oryzanol [49-51] that are present in rice bran might be extracted in the least polar fraction according to their partition coefficient. Alternatively, hydrophilic constituents such as polyphenols, GABA, and reducing sugars are possibly extracted by polar extractant $[52,53]$. The active compound(s) in the extract might have inhibitory properties on the adipocytes differentiation.

Interestingly, the OROSM of absolute methanol extract at concentration of $100 \mu \mathrm{g} / \mathrm{ml}$ and $200 \mu \mathrm{g} / \mathrm{ml}$ were higher than the control. The results of the MTT assay also showed that the absolute methanol extract was not only non-cytotoxic to the cell but it increased the cell viability of preadipocytes at these concentrations. This indicated that the compounds extracted by absolute methanol might promote the growth of the adipocytes. These results were contradicted with the study done by Ho et al., [54] which used methanol extraction on GBR, reported $49 \%$ of inhibition in reduces the OROSM. Further studies are needed to investigate and identify compounds that could contribute to this observation.

\section{Glycerol level}

Lipolysis is a catabolic process that hydrolyzes stored triglycerides in adipose tissue to release free fatty acid and glycerol. Thus, lipolysis of fat cells can regulate the homeostasis of energy by controlling the release of fatty acids and glycerol into plasma [55]. The lipolytic effect of GBR extracts was investigated through the measurement of glycerol released in culture medium after $24 \mathrm{~h}$ incubation, as shown in Figure 3. All the GBR extracts stimulated mild lipolysis by induced 1.22-1.83 fold greater release of glycerol into the culture medium than control. Toluene extract at concentration of $300 \mu \mathrm{g} / \mathrm{ml}$ showed the highest glycerol release content of adipocytes with 1.83 fold of increase and followed by hexane extract at concentration of $200 \mu \mathrm{g} / \mathrm{ml}$ (1.76 fold). Absolute methanol extract at concentration of $200 \mu \mathrm{g} / \mathrm{ml}$ showed the lowest glycerol release content of adipocytes with 1.22 fold of increase than control.

Lipolysis in adipocytes is known to be signaled by the activation of intracellular cAMP level, which in turn activates protein kinase A and substrates such as hormone-sensitive lipase and perilipin [56]. Hormone-sensitive lipase is a key enzyme in the mobilization of free fatty acids from adipocytes [56]. According to Ho et al., [54], hormone-sensitive lipase was found to be up-regulated in mice group that administrated with GBR and hypothesized that vitamin E, oryzanol and GABA were the active compounds that improve lipid metabolism in obese mice. This hypothesis is line with this present study where the least polar solvents extracts showed slightly better lipolytic effect than polar solvent extracts.

\section{Conclusions}

In conclusion, GBR extracts especially least polar and intermediate polar solvent extracts showed inhibition on pancreatic lipase, suppress adipogenesis, and stimulate lipolysis in 3T3-L1 adipocytes. This suggested that GBR may

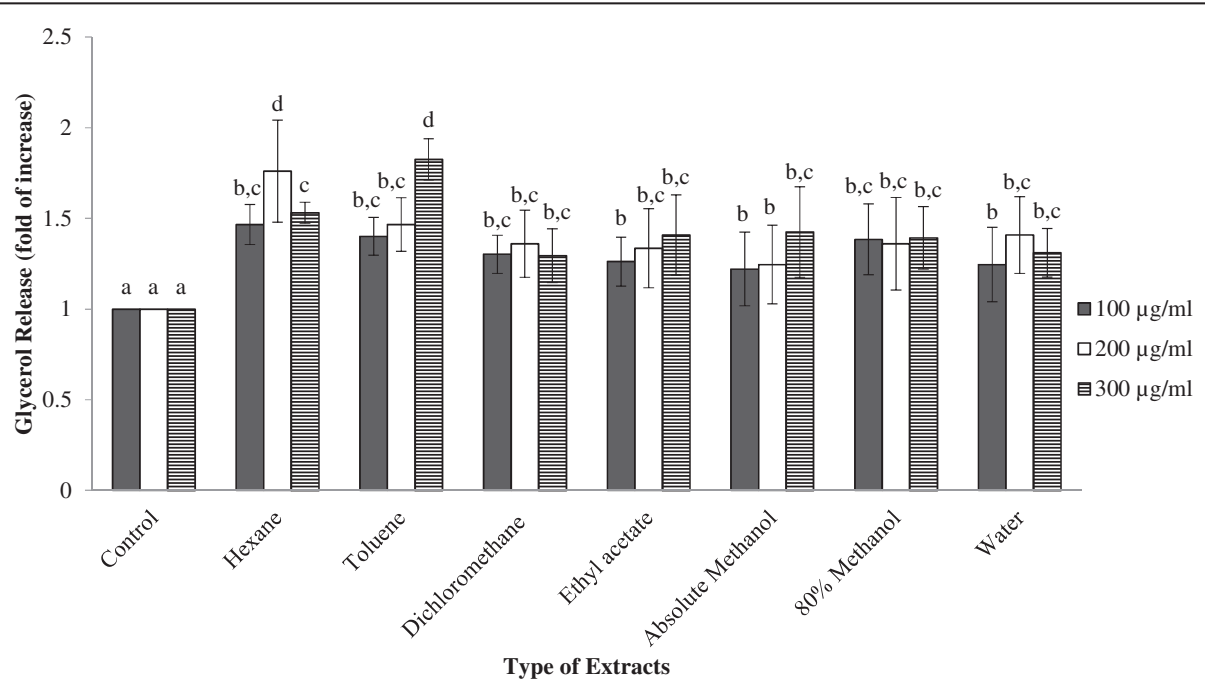

Figure 3 Extent of lipolysis based on the amount of glycerol released across different GBR extracts. Results are given as a mean value \pm S. $D$. of six replicate measurements. Bar graphs represent the relative glycerol release content of 3T3-L1 adipocytes after treated with various GBR extracts in different concentrations. ${ }^{a-d}$ Values with different lower case letters are significantly different at $p<0.05$. 
have nutraceutical potential in the treatment and/or prevention of obesity. Further study is needed to evaluate the anti-obesity effect of GBR in experimental animals and human study.

\section{Methods}

\section{Chemicals and reagents}

Dimethyl sulfoxide (DMSO), lipase (Type II; from Porcine pancreas), $p$-nitrophenyl butyrate $(p$-NPB), potassium phosphate monobasic $\left(\mathrm{KH}_{2} \mathrm{PO}_{4}\right)$, potassium phosphate dibasic $\left(\mathrm{K}_{2} \mathrm{HPO}_{4}\right)$, orlistat, 3-(4,-dimethy-lthiazol-2-yl)-2,diphenyl-tetrazoliumbromide (MTT), insulin, dexamethasone, 3-isobutyl-1-methyl-xanthine (IBMX), Oil Red O, and phosphate-buffered saline (PBS) were purchased from Sigma-Aldrich (St. Louis, MO, USA). n-Hexane, toluene, dicholoromethane, ethyl acetate, methanol, and isopropanol were purchased from Merck (Darmstadt, Germany). Dulbecco's modified Eagle's medium (DMEM), bovine calf serum (BCS), foetal bovine serum (FBS), and penicillin/ streptomycin were purchased from GIBCO (BRL Life Technologies, Grand Island, NY, USA). The water was obtained from Milli-Q water purification system (Millipore, Bedford, MA, USA). All chemicals and reagents used in the study were of analytical grade.

\section{Sample preparation}

GBR (Oryza sativa L.) was provided by Laboratory of Molecular Biomedicine, Institute of Bioscience, Universiti Putra Malaysia (Selangor, Malaysia). The GBR was grounded to fine powder, passed through the 20-mesh sieve, and stored at $-20^{\circ} \mathrm{C}$ in a tightly sealed plastic bag until further analysis.

\section{Ultrasound-assisted extraction}

The GBR was extracted according to method by Boonsiripiphat et al., [57] with modification using a sonicator. GBR (30 g) was mixed with $100 \mathrm{ml}$ of hexane in a ratio of about 1:3 (w/v). The mixture was immersed into the ultrasonic bath (Power Sonic 405, Hwashin Technology, Korea) equipped by a generator with an output of $350 \mathrm{~W}$ and input of $\mathrm{AC} 230 \mathrm{~V}$ and $40 \mathrm{kHz}$, and kept for sonication for $30 \mathrm{~min}$ with water bath temperature maintained at $40^{\circ} \mathrm{C}$. The extract was then centrifuged (Rotofix 32A, Hettich Zentrifugen, Germany) at $3500 \mathrm{rpm}$ for $10 \mathrm{~min}$ to obtain the supernatant and the rest was reextracted for another 2 times under the same conditions. The combined filtrate was filtered through Whatman No.1 filter paper (Whatman International, England) and evaporated with a rotary evaporator (Büchi Rotavapor R-200, Büchi Labortechnik AG, Switzerland) below $40^{\circ} \mathrm{C}$. The procedures of extraction were repeated in the same manner except different extraction solvents (toluene, dicholoromethane, ethyl acetate, absolute methanol, $80 \%$ methanol and deionized water) were used. The extracts were stored at $-20^{\circ} \mathrm{C}$ until analysis. The yield of extraction was calculated as follows:

$$
\text { Yield of extraction }(\%)=\frac{\mathrm{DWe}}{\mathrm{DWs}} \times 100
$$

where:

DWe $=$ dry weight of sample extract after evaporation of solvent.

DWs = dry weight of the sample powder.

The GBR extracts were dissolved in DMSO at a final concentration of $0.1 \%$ prior use.

\section{Pancreatic lipase inhibition assay}

The activity of porcine pancreatic lipase (type II) was colorimetrically evaluated through the measurement of the release of $p$-nitrophenol. The method used for measuring the pancreatic lipase activity was modified from Slanc et al., [58] and Zheng et al., [13]. Pancreatic lipase stock solutions $(1 \mathrm{mg} / \mathrm{ml})$ were prepared in a $0.1 \mathrm{M}$ potassium phosphate buffer ( $\mathrm{pH}$ 6.8) and the solutions were stored at $-40^{\circ} \mathrm{C}$. A $10 \mathrm{mM}$ solution of $p-\mathrm{NPB}$ as a substrate was prepared in acetonitrile. Absolute ethanol was then added to reach a final concentration of $3.33 \mathrm{mM}$ of $p$-NPB. Briefly, $12 \mu \mathrm{l}$ of enzyme buffer was added to $162 \mu \mathrm{l}$ of potassium phosphate buffer $(0.1 \mathrm{M}, \mathrm{pH} 7.2,0.1 \%$ Tween 80). Either $16 \mu \mathrm{l}$ of the extracts or orlistat as a positive control was then mixed into the solution and incubated for $30 \mathrm{~min}$ at $37^{\circ} \mathrm{C}$. Subsequently, $10 \mu \mathrm{l}$ of substrate solution was added and the enzymatic reactions were allowed to proceed for another $30 \mathrm{~min}$ at $37^{\circ} \mathrm{C}$. The amount of $p$-nitrophenol release in the reaction was measured at $405 \mathrm{~nm}$ using a microplate reader (SIRIO S SEAC, Italy). The absorbance reading was compared to the control, which contained same amount of buffer solution, instead of the extract. The inhibitory activity (\%) was calculated according to the following formula:

$$
\% \text { of inhibition }=\left(100-\frac{A_{405}^{\text {Extract }}}{A_{405}^{\text {Control }}}\right) \times 100
$$

where:

$$
\begin{aligned}
& A_{405}^{\text {Control }}=\text { absorbance without extract } \\
& A_{405}^{\text {Extract }}=\text { absorbance with extract. }
\end{aligned}
$$

\section{Cell culture and differentiation}

3T3-L1 preadipocytes were obtained from the American Type Culture Collection (Manassas, VA, USA). The cells were maintained in DMEM high glucose containing $10 \%(\mathrm{v} / \mathrm{v}) \mathrm{BCS}$ and penicillin/streptomycin (100 units $/ \mathrm{ml}, 100 \mu \mathrm{g} / \mathrm{ml}$, respectively) at $37^{\circ} \mathrm{C}$ in a humidified atmosphere of $95 \%$ air and $5 \% \mathrm{CO}_{2}$. Fresh medium 
were provided to the cells every 2-3 days till cells were about $80 \%$ confluence. As described previously by Ahn et al., [59], 3T3-L1 preadipocytes were seeded into 24-well plates at a density of $2 \times 10^{4}$ cells/well to differentiate preadipocytes into adipocytes and grown to confluent in three days. At this point (referred to as day 0), preadipocytes were stimulated for 3 days with a differentiation medium (10\% FBS/DMEM medium supplemented with $0.5 \mathrm{mM}$ IBMX, $1.0 \mu \mathrm{M}$ dexamethasone and $1.0 \mu \mathrm{g} / \mathrm{ml}$ insulin). On day 3 , the medium was replaced with maturation medium (10\% FBS/DMEM medium and $1.0 \mu \mathrm{g} / \mathrm{ml}$ insulin) for an additional 2 days. On day 5, the culture medium was replaced again with only $10 \% \mathrm{FBS} / \mathrm{DMEM}$, which were changed every two days until day 9. At this time, the cells exhibited a lipid-filled phenotype, which is characteristic of mature adipocytes.

\section{Treatment of GBR extracts}

To investigate the effects of GBR extracts on adipogenic differentiation, differentiating 3T3-L1 cells were treated with GBR extracts at various concentrations with medium changed every times from day 0 to day 7 . The control was treated with same medium without GBR extracts.

\section{Adipocyte cell viability assay}

MTT assay was performed to investigate the cell viability of 3T3-L1 preadipocytes according to method developed by Mosmann [60]. The cell were seeded into 96-well plate at a density of $1 \times 10^{4}$ cells/well in DMEM medium and allowed to attach for $24 \mathrm{hr}$. After that, the culture medium was replaced with $200 \mu \mathrm{l}(0,5,25,50,100,200$, $300 \mu \mathrm{g} / \mathrm{ml}$ ) of GBR extracts in DMEM medium. The cells were incubated for $72 \mathrm{hr}$ and untreated cells served as control. Ten microliters of MTT solution $(5 \mathrm{mg} / \mathrm{ml})$ in PBS ( $\mathrm{pH}$ 7.4) was added to each well. After $3 \mathrm{hr}$, the unreacted dye was removed and the formed formazan crystals were dissolved in $100 \mu \mathrm{l} /$ well DMSO. After a few minutes at room temperature to ensure that all crystals were dissolved, the plates were read on FLUOstar Omega plate reader (BMG Labtech, Offenburg, Germany), using a test wavelength of $570 \mathrm{~nm}$, a reference wavelength of $630 \mathrm{~nm}$. The cell viability (\%) was expressed as the percentage of cell viability compared to the control and calculated according the following formula:

$$
\text { Cell viability }(\%)=\frac{A_{570}^{\text {Extract }}}{A_{570}^{\text {Control }}} \times 100
$$

where:

$$
\begin{aligned}
& A_{570}^{\text {Extract }}=\text { absorbance of tested sample extract. } \\
& A_{570}^{\text {COntrol }}=\text { absorbance without tested sample extract. }
\end{aligned}
$$

\section{Oil Red $\mathrm{O}$ staining for intracellular triglycerides}

Intracellular lipid accumulation in 3T3-L1 adipocytes was measured using Oil-red $O$ that previously described by Ramírez-Zacarías et al., [61]. Briefly, the cells were washed gently twice with ice-cold PBS ( $\mathrm{pH}$ 7.4) and fixed with $10 \%$ formalin at room temperature for at least $30 \mathrm{~min}$ to $1 \mathrm{hr}$ in room temperature. After removal of the $10 \%$ formalin, wells were washed with $60 \%$ isopropyl alcohol for $5 \mathrm{~min}$ and then washed exhaustively with PBS. Wells were allowed to dry completely before the addition of filtered Oil Red $\mathrm{O}$ solution for $30 \mathrm{~min}$ at room temperature. The staining of lipid droplets in 3T3L1 adipocytes were exhaustively rinsed three times with PBS. Stained oil droplets were extracted with $100 \%$ isopropanol for $10 \mathrm{~min}$ to quantify intracellular lipids. The extracted dye was then immediately removed by gentle pipetting and its absorbance was measured spectrophotometrically at $520 \mathrm{~nm}$ using FLUOstar Omega plate reader (BMG Labtech, Offenburg, Germany). The Oil Red O-stained material (OROSM, \%) was compared to control wells containing cell culture medium without the GBR extract and calculated according the following formula:

$$
\operatorname{OROSM}(\%)=\frac{A_{510}^{\text {Extract }}}{A_{510}^{\text {Control }}} \times 100
$$

where:

$$
\begin{aligned}
& A_{510}^{\text {Extract }}=\text { absorbance of tested sample extract. } \\
& A_{510}^{\text {COntrol }}=\text { absorbance without tested sample extract. }
\end{aligned}
$$

\section{Measurement of glycerol}

Lipolysis assay was performed to evaluate the possible lipolytic activity of GBR extracts by measuring their ability to release glycerol from differentiated 3T3-L1 cells. 3T3-L1 preadipocytes were induced to adipocytes as described previously. On day 10, cells were washed with filtered Hank's Balanced Salt solution and then treated with GBR extracts for $24 \mathrm{hr}$ in filtered Hank's Balanced Salt solution with $2 \%$ bovine serum albumin. The glycerol level secreted by adipocytes was determined using enzymatic assay kit from Millipore Cat. No. OB 100 (Bedford, MA, USA). Absorbance was determined at $540 \mathrm{~nm}$ in a FLUOstar Omega plate reader (BMG Labtech, Offenburg, Germany). A standard curve was prepared, using a standard solution of glycerol at concentration of $0-104 \mu \mathrm{g} / \mathrm{ml}$ $\left(y=0.0076 x+0.0156, r^{2}=0.998\right)$. Glycerol release was then expressed as fold increase, as compared to control for comparison purpose.

\section{Statistical analysis}

Data analyzed by using software IBM SPSS version 21.0. One-way analysis of variance (ANOVA), followed by 
Duncan was applied to test for differences between groups. One-Sample $T$-Test (two tails) was performed to test for cell viability against $70 \%$. Significant differences were taken at $\mathrm{p}<0.05$.

\begin{abstract}
Abbreviations
BCS: Bovine calf serum; DMEM: Dulbecco's modified Eagle's medium; DMSO: Dimethyl sulfoxide; FBS: Foetal bovine serum; GABA: $\gamma$-aminobutyric acid; GBR: Germinated brown rice; IBMX: 3-isobutyl-1-methyl-xanthine; $\mathrm{K}_{2} \mathrm{HPO}_{4}$ : Potassium phosphate dibasic; $\mathrm{KH}_{2} \mathrm{PO}_{4}$ : Potassium phosphate monobasic; MTT: 3-(4,-dimethy-lthiazol-2-yl)-2,-diphenyl-tetrazoliumbromide; PBS: Phosphate-buffered saline; $p$-NPB: $p$-nitrophenyl butyrate; S.D.: Standard deviation; UAE: Ultrasound-assisted extraction.
\end{abstract}

\section{Competing interests}

The authors declare that they have no competing interests.

\section{Authors' contributions}

LSM performed all the experiments, analyzing the data, and wrote the manuscript. GYM provided expert statistical analysis of data and reviewed manuscript. KWB participated in performing cell culture studies. LSP was responsible for the study concept, designing and coordinating the research, and reviewed manuscript. All authors read and approved the final form of the manuscript.

\section{Acknowledgements}

The authors acknowledge Prof. Dr. Maznah Ismail from the Laboratory of Molecular Biomedicine, Institute of Bioscience, UPM for supplying the GBR sample and BERNAS, Malaysia for providing financial assistance (project no. 6372100).

\section{Author details}

'Department of Nutrition and Dietetics, Faculty of Medicine and Health Sciences, Universiti Putra Malaysia, 43400 Serdang, Selangor, Malaysia. ${ }^{2}$ Department of Veterinary Pre-Clinical Science, Faculty of Veterinary Medicine, Universiti Putra Malaysia, 43400 Serdang, Selangor, Malaysia. ${ }^{3}$ Laboratory of Molecular Biomedicine, Institute of Bioscience, Universiti Putra Malaysia, 43400 Serdang, Selangor, Malaysia.

\section{Received: 3 July 2014 Accepted: 24 October 2014}

Published: 3 November 2014

\section{References}

1. WHO: Obesity and overweight. [http://www.who.int/mediacentre/ factsheets/fs311/en/]

2. Mukherjee M: Human digestive and metabolic lipases: a brief review. J Mo/ Catal B: Enzym 2003, 22:369-376.

3. Birari RB, Bhutani KK: Pancreatic lipase inhibitors from natural sources: unexplored potential. Drug Discov Today 2007, 12:879-889.

4. Ahn JH, Liu Q, Lee C, Ahn MJ, Yoo HS, Hwang BY, Lee MK: A new pancreatic lipase inhibitor from Broussonetia kanzinoki. Bioorg Med Chem Lett 2012, 22:2760-2763.

5. Greenberg AS, Obin MS: Obesity and the role of adipose tissue in inflammation and metabolism. Am J Clin Nutr 2006, 83:461S-465S.

6. Yun JW: Possible anti-obesity therapeutics from nature: a review. Phytochem 2010, 71:1625-1641.

7. Bunkrongcheap R, Hutadilok-Towatana N, Noipha K, Wattanapiromsakul C, Inafuku M, Oku H: Ivy gourd (Coccinia grandis L. Voigt) root suppresses adipocyte differentiation in 3T3-L1 cells. Lipids Health Dis 2014, 13:88

8. Borgstrom B: Mode of action of tetrahydrolipstatin: a derivative of the naturally occurring lipase inhibitor lipstatin. Biochim Biophys Acta 1988, 962:308-316.

9. Glazer G: Long-term pharmacotherapy of obesity 2000: a review of efficacy and safety. Arch Intern Med 2001, 161:1814-1824.

10. Filippatos TD, Derdemezis CS, Gazi IF, Nakou ES, Mikhailidis DP, Elisaf MS: Orlistat-associated adverse effects and drug interactions: a critical review. Drug Saf 2008, 31:53-65.

11. Cooke D, Bloom S: The obesity pipeline: current strategies in the development of anti-obesity drugs. Nat Rev Drug Discov 2006, 5:919-931.
12. Rodgers RJ, Tschop MH, Wilding JP: Anti-obesity drugs: past, present and future. Dis Model Mech 2012, 5:621-626.

13. Zheng CD, Duan YQ, Gao JM, Ruan ZG: Screening for anti-lipase properties of 37 traditional chinese medicinal herbs. J Chin Med Assoc 2010, 73:319-324.

14. Nakai M, Fukui Y, Asami S, Toyoda-Ono Y, Iwashita T, Shibata H, Mitsunaga T, Hashimoto F, Kiso Y: Inhibitory effects of oolong tea polyphenols on pancreatic lipase in vitro. J Agric Food Chem 2005, 53:4593-4598.

15. Roh C, Jung U: Screening of crude plant extracts with anti-obesity activity. Int J Mol Sci 2012, 13:1710-1719.

16. Kim YS, Lee YM, Kim H, Kim J, Jang DS, Kim JH, Kim JS: Anti-obesity effect of Morus bombycis root extract: anti-lipase activity and lipolytic effect. J Ethnopharmacol 2010, 130:621-624.

17. Patil SB, Khan MK: Germinated brown rice as a value added rice product: A review. J Food Sci Technol 2011, 48:661-667.

18. Fitzgerald MA, McCouch SR, Hall RD: Not just a grain of rice: the quest for quality. Trends Plant Sci 2009, 14:133-139.

19. Ki O, Suzuki K, Yasui Y, Kasumi T: Bio-functional components in the processed pre-germinated brown rice by a twin-screw extruder. $J$ Food Comp Anal 2005, 18:303-316.

20. Latifah SY, Armania N, Tze TH, Azhar Y, Nordiana AH, Norazalina S, Hairuszah I, Saidi M, Maznah I: Germinated brown rice (GBR) reduces the incidence of aberrant crypt foci with the involvement of beta-catenin and COX-2 in azoxymethane-induced colon cancer in rats. Nutr J 2010, 9:16.

21. Wei Y, Shohag MJI, Ying F, Yang X, Wu C, Wang Y: Effect of ferrous sulfate fortification in germinated brown rice on seed iron concentration and bioavailability. Food Chem 2013, 138:1952-1958.

22. Moongngarm A, Saetung N: Comparison of chemical compositions and bioactive compounds of germinated rough rice and brown rice. Food Chem 2010, 122:782-788.

23. Yao $S$, Yang $T$, Z Zhao $L$, Xiong $S$ : The variation of $Y$-aminobutyric acid content in germinated brown rice among different cultivars. Sci Agr Sin 2008, 41:3974-3982.

24. Karladeea D, Suriyonga S: $Y$-Aminobutyric acid (GABA) content in different varieties of brown rice during germination. Sci Asia 2012, 38:13-17.

25. Ng LT, Huang SH, Chen YT, Su CH: Changes of tocopherols, tocotrienols, gamma-oryzanol, and gamma-aminobutyric acid levels in the germinated brown rice of pigmented and nonpigmented cultivars. J Agric Food Chem 2013, 61:12604-12611.

26. Ghavidel RA, Prakash J: The impact of germination and dehulling on nutrients, antinutrients, in vitro iron and calcium bioavailability and in vitro starch and protein digestibility of some legume seeds. LWT-Food Sci Technol 2007, 40:1292-1299.

27. Kiing C, Yiu PH, Rajan A, Wong SC: Effect of germination on $y$-Oryzanol content of selected sarawak rice cultivars. Am J Appl Sci 2009, 6:1658-1661.

28. Fernandez-Orozco R, Frias J, Zielinski H, Piskula MK, Kozlowska H, Vidal-Valverde C: Kinetic study of the antioxidant compounds and antioxidant capacity during germination of Vigna radiata cv. emmerald, Glycinemax cv. jutro and Glycine max cv. merit. Food Chem 2008, 111:622-630.

29. Nakamura S, Satoh H, Ohtsubo K: Palatable and bio-functional wheat/rice products developed from pre-germinated brown rice of super-hard cultivar EM10. Biosci Biotechnol Biochem 2010, 74:1164-1172.

30. Sun Y, Liu Z, Wang J: Ultrasound-assisted extraction of five isoflavones from Iris tectorum Maxim. Sep Purif Technol 2011, 78:49-54.

31. Sun Y, Bi J, Zhang L, Ye B: Ultrasound-assisted extraction of three bufadienolides from Chinese medicine ChanSu. Ultrason Sonochem 2012, 19:1150-1154.

32. Boonkird S, Phisalaphong C, Phisalaphong M: Ultrasound-assisted extraction of capsaicinoids from Capsicum frutescens on a lab- and pilot-plant scale. Ultrason Sonochem 2008, 15:1075-1079.

33. Rostagno MA, Palma M, Barroso CG: Ultrasound-assisted extraction of isoflavones from soy beverages blended with fruit juices. Anal Chim Acta 2007, 597:265-272.

34. Chen Y, Luo H, Gao A, Zhu M: Ultrasound-assisted extraction of polysaccharides from litchi (Litchi chinensis Sonn.) seed by response surface methodology and their structural characteristics. Innovat Food Sci Emerg Tech 2011, 12:305-309.

35. Zhu KX, Sun XH, Zhou HM: Optimization of ultrasound-assisted extraction of defatted wheat germ proteins by reverse micelles. J Cer Sci 2009, 50:266-271.

36. Picó Y: Ultrasound-assisted extraction for food and environmental samples. Trend Anal Chem 2013, 43:84-89.

37. Yang J, Kim JS, Jeong HJ, Kang HH, Cho JC, Yeom HM, Kim MJ: Determination of antioxidant and a-glucosidase inhibitory activities and 
luteolin contents of Chrysanthemum morifolium Ramat extracts. Afr J Biotechnol 2011, 10:19197-19202

38. Alothman M, Bhat R, Karim AA: Antioxidant capacity and phenolic content of selected tropical fruits from Malaysia, extracted with different solvents. Food Chem 2009, 115:785-788.

39. Thanonkaew A, Wongyai S, McClements DJ, Decker EA: Effect of stabilization of rice bran by domestic heating on mechanical extraction yield, quality, and antioxidant properties of cold-pressed rice bran oil (Oryza saltiva L.). LWT-Food Sci Technol 2012, 48:231-236.

40. Guo Z, Jin Q, Fan G, Duan Y, Qin C, Wen M: Microwave-assisted extraction of effective constituents from a Chinese herbal medicine Radix puerariae. Anal Chim Acta 2001, 436:41-47.

41. Spigno G, Tramelli L, De Faveri DM: Effects of extraction time, temperature and solvent on concentration and antioxidant activity of grape marc phenolics. J Food Eng 2007, 81:200-208.

42. Barbero GF, Liazid A, Palma M, Barroso CG: Ultrasound-assisted extraction of capsaicinoids from peppers. Talanta 2008, 75:1332-1337.

43. Rukmini C, Raghuram TC: Nutritional and biochemical aspects of the hypolipidemic action of rice bran oil: a review. J Am Coll Nutr 1991, 10:593-601

44. Zaburuth Nisha S, Jayshree N: Anti-pancreatic lipase activity of leaves of Operculina turpethum. Int J Inst Pharm Life Sci 2014, 4:59-64.

45. Kim HY, Kang MH: Screening of Korean medicinal plants for lipase inhibitory activity. Phytother Res 2005, 19:359-361.

46. Takahashi H: Lipase inhibitor derived from a defatted rice germ, U.S. patent 5,503,831; $1996: 347$.

47. Tsutsumi K, Kawauchi Y, Kondo Y, Inoue Y, Koshitani O, Kohri H: Water Extract of Defatted Rice Bran Suppresses Visceral Fat Accumulation in Rats. J Agric Food Chem 2000, 48:1653-1656.

48. ISO 10993-5: Biological evaluation of medical devices. Part 5: Tests for cytotoxicity: In vitro methods. In Biological evaluation of medical devices. Geneva, Switzerland: International Organization for Standardization; 2009

49. Nicolosi RJ, Rogers EJ, Ausman LM, Orthoefer FT: Rice bran oil and its health benefits. In Rice Science and Technology. Edited by Marshall WE, Wadsworth Jl. New York: Marcel Dekker; 1994:421-437.

50. Sayre B, Saunders R: Rice bran and rice bran oil. Lipid Tech 1990, 2:72-76.

51. Xu Z, Godber JS: Purification and Identification of Components of $Y$ Oryzanol in Rice Bran Oil. J Agric Food Chem 1999, 47:2724-2728.

52. Jang $\mathrm{S}, \mathrm{Xu} \mathrm{Z}$ : Lipophilic and hydrophilic antioxidants and their antioxidant activities in purple rice bran. J Agric Food Chem 2009, 57:858-862.

53. Wu F, Yang N, Toure A, Jin Z, Xu X: Germinated brown rice and its role in human health. Crit Rev Food Sci Nutr 2013, 53:451-463.

54. Ho J-N, Son M-E, Lim W-C, Lim S-T, Cho H-Y: Anti-obesity effects of germinated brown rice extract through down-regulation of lipogenic genes in high fat diet-induced obese mice. Biosci Biotechnol Biochem 2012, 76:1068-1074.

55. Kim J, Jang DS, Kim H, Kim JS: Anti-lipase and lipolytic activities of ursolic acid isolated from the roots of Actinidia arguta. Arch Pharm Res 2009, 32:983-987.

56. Holm C: Molecular mechanisms regulating hormone-sensitive lipase and lipolysis. Biochem Soc Technol 2003, 31:1120-1124.

57. Boonsiripiphat $\mathrm{K}$, Theerakulkait $\mathrm{C}$ : Extraction of rice bran extract and some factors affecting its inhibition of polyphenol oxidase activity and browning in potato. Prep Biochem Biotechnol 2009, 39:147-158.

58. Slanc P, Doljak B, Kreft S, Lunder M, Janes D, Strukelj B: Screening of selected food and medicinal plant extracts for pancreatic lipase inhibition. Phytother Res 2009, 23:874-877.

59. Ahn J, Lee H, Kim S, Ha T: Curcumin-induced suppression of adipogenic differentiation is accompanied by activation of Wnt/beta-catenin signaling. Am J Physiol-Cell Physiol 2010, 298:C1510-C1516.

60. Mosmann T: Rapid colorimetric assay for cellular growth and survival: Application to proliferation and cytotoxicity assays. I Immunol Methods 1983, 65:55-63.

61. Ramírez-Zacarías JL, Castro-Muñozledo F, Kuri-Harcuch W: Quantitation of adipose conversion and triglycerides by staining intracytoplasmic lipids with oil red O. Histochemistry 1992, 97:493-497.

doi:10.1186/1476-511X-13-169

Cite this article as: Lim et al.: Effect of germinated brown rice extracts on pancreatic lipase, adipogenesis and lipolysis in 3T3-L1 adipocytes. Lipids in Health and Disease 2014 13:169.

\section{Submit your next manuscript to BioMed Central and take full advantage of:}

- Convenient online submission

- Thorough peer review

- No space constraints or color figure charges

- Immediate publication on acceptance

- Inclusion in PubMed, CAS, Scopus and Google Scholar

- Research which is freely available for redistribution 